\title{
Piomiosite do piriforme em um paciente com doença de Kikuchi-Fujimoto-relato de caso e revisão da literatura*
}

\section{Piriformis Pyomyositis in a Patient with Kikuchi-Fujimoto Disease-A Case Report and Literature Review}

\author{
Antônio Augusto Guimarães Barros ${ }^{1}$ Cláudio Beling Gonçalves Soares ${ }^{1}$ Eduardo Frois Temponi ${ }^{1}$ \\ Victor Atsushi Kasuya Barbosa ${ }^{1}$ Luiz Eduardo Moreira Teixeira ${ }^{1}$ George Grammatopoulos ${ }^{2}$ \\ 1 Hospital Madre Teresa, Belo Horizonte, MG, Brazil \\ 2 The Ottawa Hospital, Ottawa, Canadá \\ Address for correspondence Antônio Augusto Guimarães Barros, \\ Hospital Madre Teresa, Belo Horizonte, MG, Brazil \\ Rev Bras Ortop 2019;54:214-218. \\ (e-mail: antonioagbarros@gmail.com).
}

\begin{abstract}
Resumo
Palavras-chave

- piomiosite

- staphylococcus aureus

- linfadenitis necrotizante histiocítica
Abstract
Keywords
- pyomyositis
- staphylococcus aureus
- histiocytic necrotizing lymphadenitis

A piomiosite primária é uma infecção bacteriana profunda do músculo esquelético. Quando não diagnosticada ou tratada, a infecção pode evoluir para sepse, choque séptico e até morte. Os autores relatam o caso de uma paciente do sexo feminino, 23 anos, apresentando piomiosite do músculo piriforme durante o tratamento da doença de Kikuchi-Fujimoto. A piomiosite é uma infecção rara, mas potencialmente grave, que pode levar ao choque séptico. Esse caso mostra a necessidade em se elevar o grau de suspeição clínica em pacientes com comprometimento do sistema imunológico, para que o tratamento seja iniciado em estágio precoce. A literatura mostra que os resultados do tratamento da piomiosite do piriforme são bons.

Primary pyomyositis is a deep bacterial infection of the skeletal muscle. If left undiagnosed and untreated, the infection spreads, leading to sepsis, septic shock, and even death. The authors report a 23-year-old female presenting with piriformis pyomyositis during a treatment for Kikuchi-Fujimoto disease. Pyomyositis is a rare but potentially severe infection that can lead to septic shock. This case shows the need for a high degree of clinical suspicion for patients with compromised immune systems to begin treatment at an early stage. The literature demonstrates that the outcomes of the treatment of piriformis pyomyositis are good.
\end{abstract}

\section{Introdução}

A piomiosite primária é uma infecção bacteriana profunda do músculo esquelético e comumente se manifesta como um

\footnotetext{
Trabalho realizado no Hospital Madre Teresa, Belo Horizonte, MG, Brasil em associação ao The Ottawa Hospital, Ottawa, Canadá. Publicado originalmente por Elsevier Ltda.
}

received

August 13, 2017

accepted

September 13, 2017

published online

April 15, 2019
DOI https://doi.org/

10.1016/j.rboe.2017.09.005. ISSN 0102-3616. abscesso local. Pode acometer pessoas de qualquer idade, mas é mais comum na primeira e segunda décadas de vida, com maior incidência entre os homens. Qualquer músculo pode ser afetado, mas a condição é mais frequente em grandes grupos musculares localizados na cintura pélvica e nos membros inferiores. ${ }^{1,2}$ De modo geral, o diagnóstico da piomiosite primária é tardio devido a sua raridade, apresentação clínica não específica e acometimento de músculos localizados em

Copyright $\odot 2019$ by Sociedade Brasileira License terms de Ortopedia e Traumatologia. Published by Thieme Revnter Publicações Ltda, Rio de Janeiro, Brazil 
compartimentos profundos. A apresentação é normalmente subaguda, e o paciente procura tratamento em média entre $5 \mathrm{e}$ 6 dias após o início dos sintomas. ${ }^{2} \mathrm{Na}$ maioria dos casos, o paciente apresenta febre, dor na região afetada e leucocitose. 0 diagnóstico é geralmente estabelecido por ressonância magnética e confirmado por exame histopatológico. $\mathrm{O}$ tratamento ocorre de acordo com o estágio da doença ao diagnóstico. ${ }^{2}$

Este estudo apresenta um caso de piomiosite do músculo piriforme em uma paciente diagnosticada com linfadenite necrótica, também conhecida como doença de Kikuchi-Fujimoto (KFD). O comitê de ética da instituição aprovou este estudo, e o termo de consentimento livre e esclarecido, por escrito, foi assinado pela família da paciente antes da inclusão no estudo.

\section{Apresentação do caso}

Uma mulher de 23 anos procurou o pronto-socorro com choque séptico secundário a uma infecção do trato respira- tório e foi internada na unidade de terapia intensiva. A paciente apresentava histórico de febre, mau estado geral e perda de peso nos 2 meses anteriores. Clinicamente, além do desconforto respiratório, havia evidências de linfadenopatia cervical e hepatoesplenomegalia. Não havia histórico médico significativo além do hipotireoidismo. A paciente relatou ausência de outras comorbidades ou viagem para outros países; ela foi tratada de uma infecção pulmonar e recebeu alta com diagnóstico de doença de Kikuchi-Fujimoto (KFD), após uma biópsia de linfonodo. Após 30 dias, a paciente se queixou de dor glútea profunda do lado esquerdo. Ela foi então encaminhada para o departamento de ortopedia.

Na consulta ortopédica, a paciente relatou dor branda na região glútea profunda. Ao exame, a paciente estava afebril, com marcha atípica, dor à palpação da região glútea profunda esquerda e sem déficits neurológicos. 0 quadril esquerdo apresentava discreta limitação de movimento: flexão de 110。, extensão de 20 。, abdução de 40 , adução de 20 , rotação
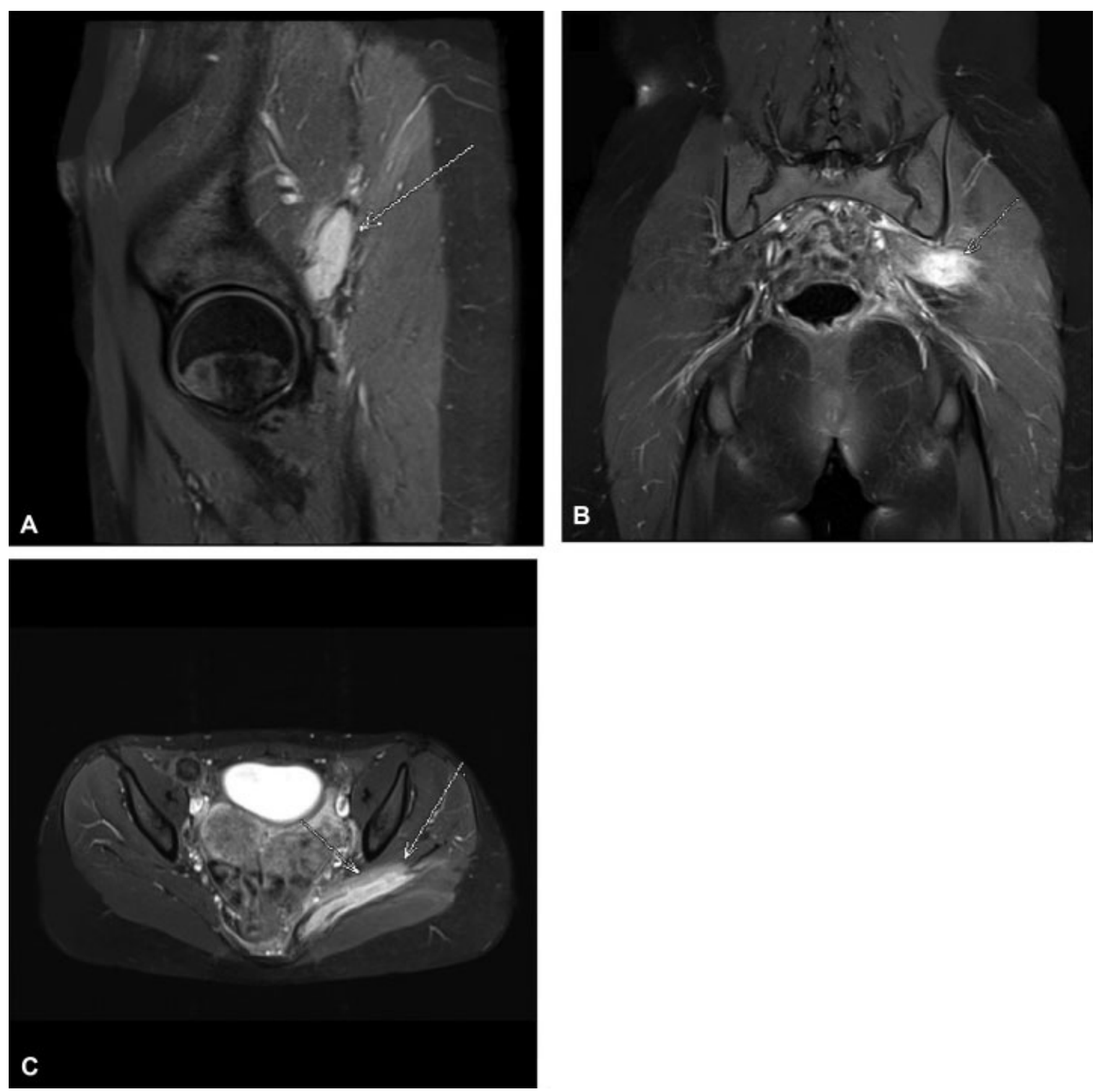

Fig. 1 Imagem de ressonância magnética com aumento de sinal no músculo piriforme esquerdo associado à presença de coleção fluida. (A) Plano sagital ponderado por densidade de prótons com supressão de gordura. (B) Imagem coronal ponderada em T1 com supressão de gordura após contraste com gadolínio. (C) Imagem axial ponderada em T1 com supressão de gordura após contraste com gadolínio. 
interna de 30॰ e rotação externa de 30。, bem como dor nos extremos de movimento. Os resultados dos exames de sangue mostraram elevação de marcadores inflamatórios. Leucócitos, $11,7 \times 10^{9} / \mathrm{L}$; proteína $\mathrm{C}$ reativa, $65 \mathrm{mg} / \mathrm{L}$; e taxa de hemossedimentação, $51 \mathrm{~mm} / \mathrm{h}$. As radiografias de ambos os quadris eram normais. A ressonância magnética foi realizada e mostrou aumento de sinal no músculo piriforme esquerdo, associado à presença de coleção fluida (-Fig. 1).

A paciente foi internada para drenagem cirúrgica aberta do músculo piriforme. Os resultados das amostras coletadas durante o procedimento mostraram a cultura positiva para Staphylococcus aureus resistente à meticilina (SARM), e o exame histopatológico com infiltrado inflamatório (-Fig. 2). $O$ resultado do antibiograma foi vancomicina e trimetoprima-sulfametoxazol com concentrações inibitórias mínimas (CIMs) de $\leq 2 \mu \mathrm{g} / \mathrm{mL} \mathrm{e} \leq 2 / 38 \mu \mathrm{g} / \mathrm{mL}$, respectivamente. A paciente foi submetida à antibioticoterapia intravenosa ( 15 $\mathrm{mg} / \mathrm{kg}$ vancomicina a cada 12 horas) durante os primeiros 10 dias, seguida por terapia oral (160 mg trimetoprima/800 mg sulfametoxazol a cada 12 horas) por até 6 semanas. A paciente se recuperou da cirurgia sem complicações e recebeu alta no $10^{\circ}$ dia. Durante a consulta de retorno 30 dias após a cirurgia, a paciente estava assintomática. Seis meses após a cirurgia, a paciente não apresentava dor e nenhuma limitação funcional.

\section{Discussão}

Até onde podemos determinar, este é o primeiro relato de caso em língua inglesa de piomiosite do músculo piriforme em um paciente com diagnóstico de KFD. A primeira descrição detalhada da piomiosite é atribuída a Scriba, em $1885 .{ }^{1} \mathrm{~A}$ doença é mais comum em países tropicais, mas sua incidência aumentou em todo o mundo. Esta maior incidência parece relacionada ao aumento do número de indivíduos com comprometimento do sistema imune (por exemplo, indivíduos com HIV, diabetes, transplante de órgãos, quimioterapia, neoplasias malignas, doenças reumáticas). As incidências e taxas de prevalência exatas não são bem conhecidas. ${ }^{2}$ A literatura contém poucos relatos de piomiosite no músculo piriforme. ${ }^{3-13}$ Diferentemente do caso aqui apresentado, muitos desses relatos discutiram pacientes com ciática e sintomas graves que procuraram atendimento médico em pronto-socorro e apresentaram grandes mudanças nos marcadores laboratoriais de infecção (-Tabela 1).

Em um estudo que avaliou 676 casos de piomiosite, a idade média foi de 28,1 anos; em $26,3 \%$ dos casos, o quadríceps foi o grupo muscular mais afetado, e, em $16,6 \%$ dos pacientes, houve acometimento de mais de um grupo muscular. Em muitos casos, as bactérias infectantes não foram identificadas; no entanto, S. aureus foi responsável por $77 \%$ dos casos identificados. ${ }^{2}$ A patogênese da piomiosite ainda não é completamente compreendida. Acredita-se que seja uma complicação de bacteremia transitória associada a uma anomalia do tecido muscular local. ${ }^{14} \mathrm{~A}$ evolução da piomiosite pode ser clinicamente dividida em três estágios. ${ }^{2,14} \mathrm{~A}$ fase invasiva é subaguda e ocorre entre uma e três semanas. $\mathrm{O}$ paciente apresenta dor local, edema, febre e leucocitose. Não
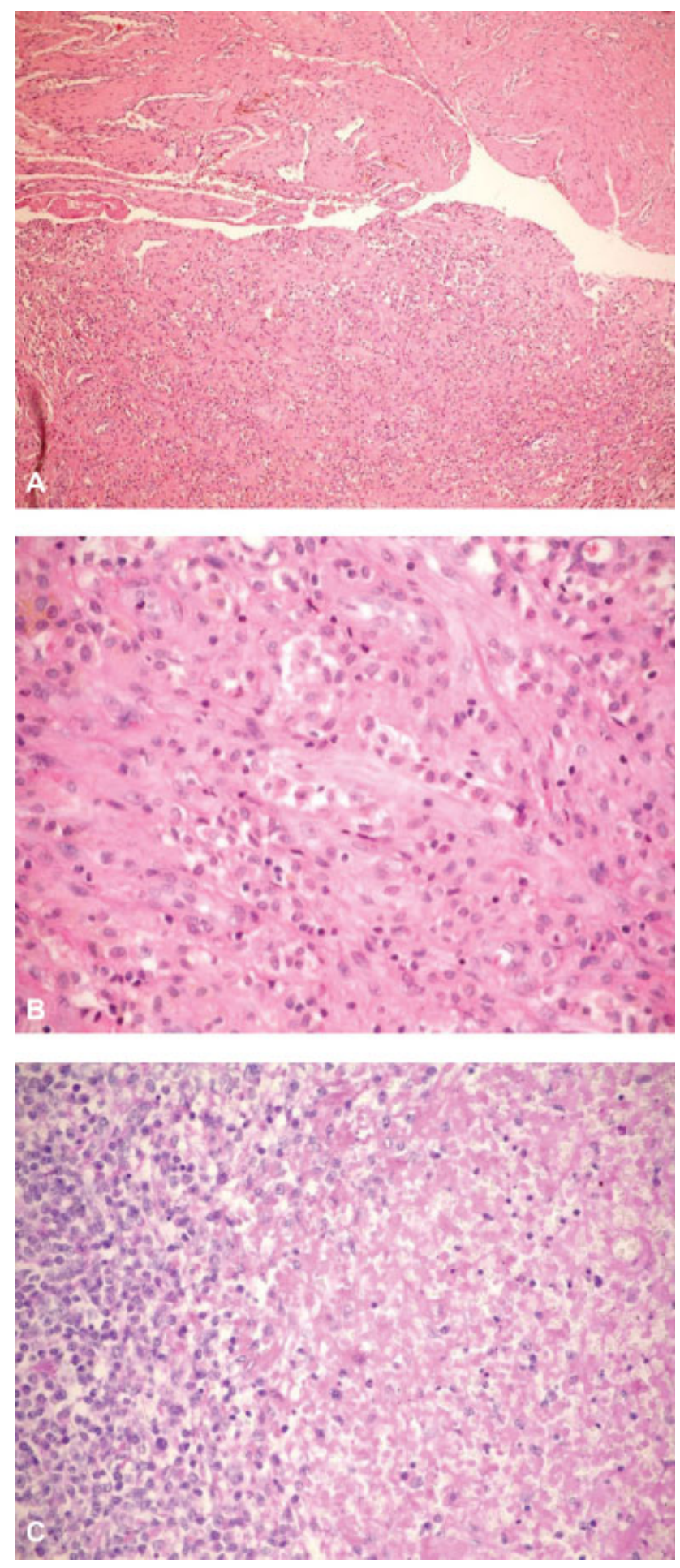

Fig. 2 (A) Fotomicrografia da piomiosite do piriforme. Tecido fibromuscular com infiltrado inflamatório linfo-histiocitário moderado (hematoxilina-eosina, $\times 100$ ). (B) Fotomicrografia da piomiosite do piriforme, maior aumento do tecido inflamatório (hematoxilinaeosina, $\times 400)$. (C) Fotomicrografias de biópsia de linfonodo mostrando necrose focal cercada por debris cariorréticos, histiócitos e linfócitos plasmocitoides (hematoxilina-eosina, ×400).

há pus. Este estágio pode regredir ou progredir para o próximo estágio. 0 estágio supurativo, quando geralmente o diagnóstico é estabelecido, é caracterizado por agravamento dos sintomas, febre e formação de abscesso. No 
Tabela 1 Características da piomiosite com acometimento do músculo piriforme já relatada na literatura em língua inglesa no MEDLINE/PubMed

\begin{tabular}{|c|c|c|c|c|}
\hline Autores & $\begin{array}{l}\text { Número } \\
\text { de casos }\end{array}$ & $\begin{array}{l}\text { Idade } \\
\text { (anos) }\end{array}$ & Tratamento & Desfecho \\
\hline Burkhart et al ${ }^{3}$ & 1 & 69 & Aspiração orientada por TC & $\begin{array}{l}\text { Resolução completa dos sintomas e retorno às ativi- } \\
\text { dades esportivas. }\end{array}$ \\
\hline Chusid et $\mathrm{al}^{4}$ & 1 & 17 & Antibióticos intravenosos & $\begin{array}{l}\text { No } 10^{\circ} \text { dia de tratamento, os marcadores inflama- } \\
\text { tórios do paciente voltaram ao normal. }\end{array}$ \\
\hline \multirow[t]{3}{*}{ Wong et $\mathrm{al}^{5}$} & 3 & 45 & Antibióticos intravenosos & $\begin{array}{l}\text { A dor diminuiu gradualmente e os marcadores infla- } \\
\text { matórios voltaram ao normal. }\end{array}$ \\
\hline & & 58 & Aspiração orientada por TC & $\begin{array}{l}\text { A febre e a dor diminuíram após a drenagem e } 2 \\
\text { semanas de antibióticos intravenosos. }\end{array}$ \\
\hline & & 71 & Antibióticos intravenosos & $\begin{array}{l}\text { A dor e a febre diminuíram e a miosite se resolveu } \\
\text { após } 2 \text { semanas de antibióticos intravenosos. }\end{array}$ \\
\hline Wong et $\mathrm{al}^{6}$ & 1 & 31 & Antibióticos intravenosos & $\begin{array}{l}\text { Os parâmetros sanguíneos e os sintomas clínicos } \\
\text { melhoraram ao longo do tratamento. } \\
\text { Ausência de sintomas residuais. }\end{array}$ \\
\hline Chong et $\mathrm{al}^{7}$ & 1 & 30 & Antibióticos intravenosos & $\begin{array}{l}\text { Uma consulta de acompanhamento na clínica mos- } \\
\text { trou a recuperação completa com normalização da } \\
\text { velocidade de hemossedimentação e da concentra- } \\
\text { ção de proteína } C \text { reativa. }\end{array}$ \\
\hline Toda et $\mathrm{al}^{8}$ & 1 & 06 & Antibióticos orais & $\begin{array}{l}\text { O acompanhamento final aos } 6 \text { meses revelou } \\
\text { amplitude completa de movimento da articulação do } \\
\text { quadril e ausência de dor. }\end{array}$ \\
\hline Koda et al $^{9}$ & 1 & 42 & $\begin{array}{l}\text { Drenagem cirúrgica } \\
\text { aberta seguida por } \\
\text { tratamento com } \\
\text { antibióticos }\end{array}$ & $\begin{array}{l}\text { Alívio dramático da dor após a cirurgia. } \\
\text { Paciente voltou ao trabalho após } 2 \text { meses. }\end{array}$ \\
\hline Giebaly et al ${ }^{10}$ & 1 & 18 & Antibióticos intravenosos & $\begin{array}{l}\text { Resolução completa dos sintomas e retorno às ativi- } \\
\text { dades esportivas após } 6 \text { meses. }\end{array}$ \\
\hline Colmegna et al ${ }^{11}$ & 1 & 18 & Aspiração orientada por TC & $\begin{array}{l}\text { Após } 4 \text { semanas, o paciente estava totalmente } \\
\text { recuperado. }\end{array}$ \\
\hline Kinahan et al ${ }^{12}$ & 1 & 22 & Antibióticos intravenosos & $\begin{array}{l}\text { Recuperação completa após } 6 \text { semanas de antibioti- } \\
\text { coterapia intravenosa. }\end{array}$ \\
\hline Gaughan et al ${ }^{13}$ & 1 & 34 & Antibióticos intravenosos & $\begin{array}{l}\text { Após } 8 \text { semanas, o paciente ainda andava com } \\
\text { muletas e dependia de analgésicos. }\end{array}$ \\
\hline $\begin{array}{l}\text { Barros et al } \\
\text { (caso atual) }\end{array}$ & 1 & 23 & $\begin{array}{l}\text { Drenagem cirúrgica } \\
\text { aberta seguida por } \\
\text { tratamento com } \\
\text { antibióticos }\end{array}$ & Assintomática após 6 meses. \\
\hline
\end{tabular}

Abreviação: TC, tomografia computadorizada.

entanto, devido à sua localização profunda, os sinais clássicos de inflamação podem estar ausentes. Se a fase supurativa não for diagnosticada e tratada, há disseminação da infecção, levando à fase tardia, caracterizada por sepse, choque séptico e até morte. ${ }^{2,14}$

Os exames laboratoriais são capazes de detectar leucocitose variável, principalmente no estágio invasivo, mas o desvio à esquerda ocorre durante o estágio supurativo. Os marcadores inflamatórios velocidade de hemossedimentação e proteína $C$ reativa são elevados, mas não são específicos. As hemoculturas são estéreis em 70 a $80 \%$ dos casos. ${ }^{14}$ A ressonância nuclear magnética é a metodologia de imagem importante no diagnóstico de piomiosite; revela inflamação muscular difusa e a subsequente formação de abscesso. A administração de contraste auxilia a detecção de abcessos. A biópsia muscular associada à cultura de tecidos continua sendo o padrão-ouro para o diagnóstico. ${ }^{14}$ No presente caso, a paciente era assintomática, sem efeitos sistêmicos de infecção e com poucas alterações nos exames laboratoriais, provavelmente pelo uso de trimetoprima e sulfametoxazol para prevenção de infecções oportunistas durante o tratamento do linfoma.

A piomiosite é tratada de acordo com a fase em que é diagnosticada. Na fase inicial, distúrbios inflamatórios difusos podem ser tratados apenas com antibióticos. ${ }^{7}$ Entretanto, após a formação de um abcesso, a drenagem deve ser realizada e seguida pela antibioticoterapia. ${ }^{9}$ Esse tratamento permite a recuperação completa sem sequelas na maioria dos casos. A drenagem pode ser feita por meio de punção percutânea guiada por ultrassonografia ou TC, e a cirurgia aberta é realizada em casos de drenagem incompleta, com danos 
musculares graves que exigem debridamento extenso. A antibioticoterapia intravenosa deve ser mantida durante os primeiros 7 a 10 dias e seguida pelo tratamento oral por até 6 semanas. $^{2}$

Nosso relato apresenta uma associação entre a piomiosite do piriforme e a rara KFD. A KFD é uma doença benigna e geralmente autolimitante que acomete principalmente mulheres com menos de 30 anos de idade. A maioria dos casos se resolve em 6 meses. Sua etiologia é desconhecida, mas uma correlação com infecções virais e distúrbios autoimunes tem sido relatada. 0 paciente apresenta febre, fadiga, aumento de volume dos linfonodos e sintomas do trato respiratório superior. Muitas vezes, o diagnóstico é confundido com outras doenças, como o linfoma, e é confirmado pela biópsia de linfonodo. ${ }^{15}$

\section{Conclusão}

A piomiosite é uma infecção rara e possivelmente grave que pode levar ao choque séptico. 0 caso apresentado neste artigo mostra a necessidade de um alto nível de suspeita em pacientes com comprometimento do sistema imune para que o tratamento possa ser instituído em um estágio inicial. A literatura médica revista mostra que, apesar da infecção grave, o resultado do tratamento tende a ser muito bom.

Conflitos de interesse

Os autores declaram não haver conflitos de interesse.

\section{Referências}

1 Scriba J, Beitrang Z. Aetiologie der myositis acuta. Deutsche Zeit Chir. 1885;22:497-502
2 Bickels J, Ben-Sira L, Kessler A, Wientroub S. Primary pyomyositis. J Bone Joint Surg Am 2002;84-A(12):2277-2286

3 Burkhart BG, Hamson KR. Pyomyositis in a 69-year-old tennis player. Am J Orthop 2003;32(11):562-563

4 Chusid MJ, Hill WC, Bevan JA, Sty JR. Proteus pyomyositis of the piriformis muscle in a swimmer. Clin Infect Dis 1998;26(01):194-195

5 Wong $\mathrm{CH}$, Choi SH, Wong KY. Piriformis pyomyositis: a report of three cases. J Orthop Surg (Hong Kong) 2008;16(03):389-391

6 Wong LF, Mullers S, McGuinness E, Meaney J, O'Connell MP, Fitzpatrick C. Piriformis pyomyositis, an unusual presentation of leg pain post partum-case report and review of literature. J Matern Fetal Neonatal Med 2012;25(08):1505-1507

7 Chong KW, Tay BK. Piriformis pyomyositis: a rare cause of sciatica. Singapore Med J 2004;45(05):229-231

8 Toda T, Koda M, Rokkaku T, Watanabe H, Nakajima A, Yamada T, et al. Sciatica caused by pyomyositis of the piriformis muscle in a pediatric patient. Orthopedics 2013;36(02):e257-e259

9 Koda M, Mannoji C, Watanabe H, Nakajima A, Yamada T, Rokkaku $\mathrm{T}$, et al. Sciatica caused by pyomyositis of the piriformis muscle. Neurol India 2013;61(06):668-669

10 Giebaly DE, Horriat S, Sinha A, Mangaleshkar S. Pyomyositis of the piriformis muscle presenting with sciatica in a teenage rugby player. BMJ Case Rep 2012;2012:bcr1220115392. Doi: 10.1136/ bcr.12.2011.5392

11 Colmegna I, Justiniano M, Espinoza LR, Gimenez CR. Piriformis pyomyositis with sciatica: an unrecognized complication of "unsafe" abortions. J Clin Rheumatol 2007;13(02):87-88

12 Kinahan AM, Douglas MJ. Piriformis pyomyositis mimicking epidural abscess in a parturient. Can J Anaesth 1995;42(03): 240-245

13 Gaughan E, Eogan M, Holohan M. Pyomyositis after vaginal delivery. BMJ Case Rep 2011;2011:bcr0420114109. Doi: 10.1136/bcr.04. 2011.4109

14 Agarwal V, Chauhan S, Gupta RK. Pyomyositis. Neuroimaging Clin N Am 2011;21(04):975-983, x

15 Marunaka H, Orita Y, Tachibana T, Miki K, Makino T, Gion Y, et al. Kikuchi-Fujimoto disease: evaluation of prognostic factors and analysis of pathologic findings. Acta Otolaryngol 2016;136(09): 944-947 